\title{
LITERATUUR BETREFFENDE HET NATUURWETENSCHAPPELIJK ONDERZOEK IN SURINAME GEDURENDE DE OORLOGSJAREN
}

\author{
DOOR \\ P. WAgENAAR HUMmelinck
}

Daadwerkelijke belangstelling voor natuurwetenschappelijke onderzoekingen in Suriname in oorlogstijd, openbaarde zich slechts bij hen, die verbonden waren aan inrichtingen welke het verrichten van wetenschappelijk werk tot taak hebben.

Zooals ook uit de hieronder besproken literatuur blijkt, werden op het Landbouwproefstation (prof. STAHEL en dr. GEIJSKES) de meeste wetenschappelijke onderzoekingen verricht, terwijl het werk van het Departement Landbouw-Economische Zaken en de Geneeskundige School, met hun veel grootere bezetting, meer op de praktijk was georiënteerd.

Hoewel een volledig beeld pas kan worden verkregen, wanneer de resultaten van de laatste jaren geheel in druk zijn verschenen. moge dit overzicht van de, van September 1939 tot en met December 1945 gepubliceerde literatuur, reeds eenigen indruk geven van het mooie werk dat in oorlogstijd, op wetenschappelijk gebied, in het vrije Rijksdeel Suriname is verricht.

A. B. Droogleever Fortuyn, 1945. Wild rats and mice in Paramaribo. Uitg. Volksgezondheid Suriname, 13 pp.

De schrijver onderzocht 31 bruine ratten (Rattus norvegicus), 1 jonge rat van een onbekende soort en 84 huismuizen (Mus musculus). $\mathrm{Al}$ deze dieren worden nauwkeurig op de waarde van enkele systematische kenmerken onderzocht, terwijl er ook nog iets over hun parasieten wordt medegedeeld.

J. FrICKERS, 1945. Het zandsavannen veeteeltvraagstuk in Suriname. Meded. Landb. Econ. Zaken Suriname 4, 26 pp.

Daar de veestapel in de Surinaamsche kuststreek niet groot genoeg is om in de behoefte aan rundvleesch te voorzien, is in den loop van 
den tijd herhaaldelijk de vraag gerezen of de Benedenlandsche Savannen niet geschikt zouden zijn voor het oprichten van extensieve veeteeltbedrijven. De meeningen hierover waren en zijn ook thans nog zeer verdeeld.

Bij de zeer bescheiden proeven waarover verslag wordt uitgebracht gelukte het niet, om met 33, uit Suriname en Britsch-Guyana (Rupununi Savanne) afkomstige runderen, bij de Indianen op de Powakka Savannen (Boven Suriname) een veefokkerij op te zetten. Hoewel het mislukken van den proef ten deele moet worden geweten aan de ondeskundigheid van de Indianen, is, volgens den schrijver, de voornaamste reden toch de geringe voedingswaarde van de natuurlijke grassen. Meer uitgebreide en langduriger proeven over de savannenveeteelt in Britsch-Guyana doen echter vermoeden, dat op de, door bemesting en het planten van nieuwe grassen verbeterde savanne, rundveeteelt mogelijk is, indien geregeld een volledig mineraalmengsel wordt bijgevoerd. In hoeverre op deze wijze een loonend bedrijf kan worden opgebouwd, staat nog niet vast, en de schrijver raadt daarom aan, eerst de verbetering en de uitbreiding van den bestaanden veestapel in de kuststreek ter hand te nemen.

Hoewel uit de gegevens welke in deze publicatie zijn verzameld duidelijk blijkt dat omtrent de waarde van de Surinaamsche zandsavannen zeker géén groote verwachting mag worden gekoesterd, schijnt het toch wel noodig eerst nog een aantal verschillende savannen nauwkeurig te onderzoeken - waarbij ook het doen van eenvoudige voedingsproeven niet mag worden nagelaten - alvorens een beslissend oordeel omtrent de waarde van de Benedenlandsche Savannen voor halfwilde veeteeltbedrijven kan worden uitgesproken.

D. C. GeIJSKES, 1940. Voorraadsinsecten van rijst in Suriname met aanwijzingen ter bestrijding. Bull. Landbouwproefst. Suriname 55, 34 pp., 2 figg., tab. Deze publicatie werd reeds besproken in W.I.Gids 23, jrg. 22, p. 256.

D. C. Geijskes, 1940. De wantsenplaag in de rijst. De Surinamer 1940, 20 Sept., 3 pp.

Tijdens den bloei van de rijst verschijnt in sommige Surinaamsche districten de padi-wants (Mormidea poecila; fjo-fjo; ghandi) soms in groote getale op de aren en zuigt de jonge, nog met melksap gevulde korrels leeg. Waar de dieren vandaan komen, is nog een open vraag; algemeen wordt aangenomen dat ze op wilde grassen leven. $\mathrm{Na} 2-3$ weken, zoodra de inhoud van de korrel in een vaste substantie overgaat, verhuizen de gevleugelde wantsen naar jongere velden. $\mathrm{Na}$ ongeveer 2 weken rijkelijke voeding begint elk wijfje gemiddeld 200 eieren af te zetten, die na 5 dagen uitkomen. Indien het veld dan niet binnen 20 dagen wordt geoogst, is er weer een nieuwe generatie larven gereed voor een aanval op de bloeiende rijstvelden in de buurt. Er zijn plaatsen, waar het verlies zeker $50 \%$ van den anders te verwachten oogst bedraagt!

Het is dus zaak van het begin af de wantsenplaag zoo krachtig mogelijk te bestrijden, wat het best kan gebeuren op een wel buiten- 
gewoon eenvoudige manier: het wegvangen van de volwassen dieren met een, thans in het groot aangemaakt vangnet, waarmede men horizontaal over de aren slaat.

D. C. Geijskes, 1940. Notes on Odonata of Surinam. I. Rimanella arcana Needham and its nymph (Odon. Zyg.). Revista Entomol. II, p. 173-179, 8 figg.

Beschrijving van een onbekende, buitengewoon merkwaardige libellenlarve uit de Waremapan-kreek (Boven Marowijne).

D. C. Geijskes, 1941. Notes on Odonata of Surinam. II. Six mostly new zygopterous nymphs from the coastland waters. Ann. Entom. Soc. America 34, p. 719-734, 6 figg.

Nauwkeurige beschrijvingen met prachtige afbeeldingen van de nymphen van de libellen Lestes tenuatus, Aeolagrion demararum, Acanthagrion ascendens, Leptobasis vacillans, Ceratura capreola en Ischnura ramburi credula.

D. C. GeijSkes, 1942. Observations on temperature in a tropical river. Ecology 23, p. 106-110, 3 figg. De temperatuur van het water van de Marowijne, vanaf de bronnen $\left(\right.$ ca $22^{\circ} \mathrm{C}$ ) tot dicht bij den mond (gemiddeld ca $30^{\circ}$ ), wordt vergeleken met de luchttemperatuur (resp. gemiddeld ca 22 en $27^{\circ}$ ), waardoor wij een inzicht krijgen in de warmteverhoudingen van een tropische rivier.

D. C. Geijskes, 1942. Met de Oajana's op stap. Verslag van een reis naar de Litani (Boven Marowijne) in Suriname. Depart. Landbouwproefst. Suriname, 139 pp, 13 figg.

Het doel van de reis (24 Juni-9 Sept. '39) was: 1e het opsporen van de planten welke de Oajana-Indianen voor de bereiding van hun pijlgif (oerali =curare) gebruiken; 2e het bijeenbrengen van gegevens omtrent de dierenwereld van het achterland van de Litani. Verder zouden er gegevens worden verzameld over de Oajana's en hydrographische waarnemingen worden verricht.

Met dit alles is Geijskes wonderwel geslaagd! De Oajana's legden hem bij het aanwijzen der gifplanten geen moeilijkheden in den weg, zoodat een volledig herbariummateriaal kon worden verzameld en levende exemplaren naar Paramaribo konden worden gebracht. Uit het achterland van de Litani kon een groote insectencollectie worden bijeengebracht, terwijl uit de rijke vangsten der Indianen een overzicht van de vischfauna werd verkregen. Van bijzonder wetenschappelijk belang bleken enkele kreken welke van het grensgebergte afstroomen; zij herbergen tal van interessante soorten, welke elders in Suriname schijnen te ontbreken.

Aan het plantendek van de bergtoppen in het grensgebied werd bijzondere aandacht geschonken. Er werden gesteentemonsters ver- 
zameld en uitgebreide temperatuur-metingen van het rivierwater en de lucht verricht. Wat de Oajana-Indianen betreft werden in het bijzonder hun namen voor planten en dieren genoteerd, de inwoners en de ligging der dorpen geregistreerd en gegevens verzameld over het technisch gedeelte van de wespenproef.

Een woord van hulde aan den schrijver van dit eenvoudig en toch zoo buitengemeen boeiende reisverhaal in dagboekvorm, mag hier niet achterwege blijven. Het boekje bevat een schat van natuurhistorische en volkenkundige gegevens, maar het grootste geschenk dat de schrijver van deze rustige, zakelijke regelen te geven heeft, is zijn liefde voor de levende natuur welke het geheel doorstraalt en waardoor de lezer onwillekeurig wordt bevangen door een groot verlangen naar het schoone land van Suriname.

D. C. GeijSkes, 1942. De vegetatie van het kustgebied. Suriname Waakt I, Sept., p. 10-12.

Uit onderzoekingen in het moerassige kustgebied van Suriname blijkt, hoe het voorkomen van bepaalde plantensoorten ons belangrijke aanwijzingen kan geven over den toestand van bodem en grondwater. Beter dan door een onderzoek van grondmonsters en andere bodemkundige waarnemingen op één bepaalden tijd gedaan, kunnen wij dikwijls door de planten zelve worden ingelicht omtrent de gemiddelde waarden van de omstandigheden ter plaatse.... indien wij deze levende meetinstrumenten slechts als zoodanig hebben leeren gebruiken. Dat hierin een belangrijk hulpmiddel ligt voor de praktijk bij prospectie naar nieuwe gronden voor bepaalde gewassen, behoeft nauwelijks betoog. Van bijzonder belang wordt een floristisch en planten-sociologisch onderzoek, waar het er om gaat de landbouwkundige waarde van een bepaalde landstreek uit lucht-foto's te beoordeelen.

D. C. Geijskes, 1942. De wespen- en mierenproef der Oajana-Indianen. Suriname Waakt I, Oct., p. 14-15. Een beschrijving van den merkwaardigen ritus waarvan DE GOEJE (Bijdr. Taal- Land-Volkenk. N.Indië Ioo, 1941, p. 108-111) een samenvatting heeft gegeven. Tijdens GeIJSKEs' verblijf bij de Oajana's aan de Litani (zie: Met de Oajana's op stap, 1942, p. 114-116) bleek hem dat voor de malaké 2 mieren- en 8 wespensoorten in gebruik zijn. De mierensoorten werden beide verzameld; van de wespensoorten konden er 5, waaronder de belangrijkste, achterhaald worden.

D. C. Geijskes, 1943. Notes on Odonata of Surinam. III. The genus Coryphaeschna, with descriptions of a new species and of the nymph of $C$. virens. Entomol. Nerws 54, p. 61-72, 2 figg.

De nieuwe soort, $C$. dentata, werd in de Paloemeu verzameld.

D. C. Geijskes, 1943. Notes on Odonata of Surinam. IV. Nine new or little known zygopterous nymphs 
from the inland waters. Ann. Entom. Soc. America 36 , p. $165-184,7$ tabb.

Beschrijving van de nymphen van Oxystigma petiolatum, Hetaerina dominula, H. moribunda, H. sp., Argia insipida, Argiallagma minutum, Telebasis sanguinalis, Acanthagrion adustum en A. indefensum.

(D.C. GEIJSKES), 1944. Zes maanden in de binnenlanden. Op zoek naar wilde rubberboomen. De West 45, 24 Jan.

Bericht over een zeer geslaagden tocht naar den Boven Coppename, waarbij het Wilhelmina en Bakhuisgebergte werden geëxploreerd en den Tafelberg (voor het eerst!) werd beklommen. Behalve veel botanisch materiaal - waaronder levende plantjes van Hevea-soorten - werden een zoölogische en geologische collectie bijeengebracht en topografische waarnemingen verricht.

D. C. Geijskes, 1945. Plants of the Surinam coastland. Journ. N. York Bot. Garden 46, p. 229-236, 5 figg.

Een geillustreerd artikel van ongeveer denzelfden inhoud als het stuk in Suriname Waakt over „De vegetatie van het kustgebied”.

J. E. Heesterman, 1939. Onderzoekingen betreffende het vriespunt van de melk van Surinaamsche koeien. Gouvern. Advertentieblad Ioo, Verslag Keuringsdienst, p. (3)-(4).

De bepaling van de vriespuntsverlaging van melk behoort tot de meest betrouwbare methoden om toevoeging van water aan melk aan te toonen. Waar men b.v. bij de beoordeeling met de vetvrije droogrest, de minder sterke vervalschingen met gemiddeld $12 \%$ watertoevoeging over het hoofd moet zien, kan men volgens een beoordeeling aan de hand van het vriespunt, gemiddeld ten hoogste $4 \%$ toelaten. Nadat de bepaling van het vriespunt, eind September 1939, regelmatig werd ingeschakeld in het dagelijksch melkonderzoek, werden de aantallen proces-verbaal wegens watervervalsching dan ook 3 tot 4-maal zoo groot!

J. D. OPPENHEIM, 1945. Klimatologische beschouwingen in verband met de citruscultuur in Suriname. Meded. Landb. Econ. Zaken Suriname 3, 33 pp.

$\mathrm{Na}$ een grondige studie van de temperatuur, den regenval en het optreden van droogte-perioden in verband met de citruscultuur op de zware gronden van het laaggelegen kustgebied, komt de schrijver tot den slotsom dat: $a$ het zeer goed mogelijk is dat de in Suriname optredende afwijkingen van het in de U.S.A. gestandaardiseerde fruit (in kleur, dikte der tusschenschotten en verhouding suiker: zuur) in verband staan met de hooge gemiddelde temperatuur; $b$ het diffuus worden van den bloei en daardoor van den oogst, in verband staat 
met de wisselvalligheid van den regenval en dus als een normaal verschijnsel moet worden aanvaard, hoewel de kans op een bloeiconcentratie bij den overgang van een droog naar een nat seizoen grooter is dan in de andere maanden van het jaar; $c$ op voor de citruscultuur geschikte gronden deze cultuur loonend zonder irrigatie kan worden bedreven.

Gerold Stahel, 1940. Corticium areolatum, the cause of the areolate leaf spot of Citrus. Phytopathology 30 , p. 119-130, 7 figg.

Een nauwkeurige beschrijving, met duidelijke afbeeldingen, van het voorkomen, de symptomen en, voor 't eerst ook van den verwekker van de ringvlekken-ziekte, welke, bij langdurig regenweer, de aanplantingen van zekere Citrus-soorten (vooral van de grape-fruit) in Suriname zoo gevoelig kan teisteren.

Doeltreffender dan door het verzamelen en verbranden van de aangetaste bladeren, kan deze ziekte worden bestreden door, in het begin van den regentijd, den grond onder de boomen met bordeausche-pap te besproeien. Mochten de planten dan toch nog in belangrijke mate door de ringvlekken- schimmel blijken te zijn aangetast, dan moeten de bladeren, en wel in het bijzonder de onderkanten, met hetzelfde mengsel worden bespoten.

Gerold Stahel, 1941. The effect of carbon bisulphide on the germination of paddy. Trop. Agric. I8, p. 200-203.

De noodzaak om opgeslagen paddy tegen insectenschade te vrijwaren deed den wensch opkomen iets te weten van den invloed van zwavelkoolstof op den kiemkracht van zaai-paddy. Hoewel het te verwachten was dat de giftige werking van zwavelkoolstof-damp nauw zou samenhangen met het watergehalte van den korrel, gaven de proeven toch nog enkele onverwachte resultaten.

Aan de lucht gedroogde paddy met een vochtigheidsgehalte van $14 \%$ kan, zonder schade, 7 dagen lang met de gewone, voor desinfecties gebruikelijke concentratie worden behandeld, terwijl zij bij een vochtigheidsgehalte van $13 \%$ reeds een behandeling van 14 dagen kan verdragen. Zeer droge korrels, met minder dan 9\% vocht, ontkiemen nog na een 14-daagsche behandeling met verzadigden damp of zelfs met vloeibare zwavelkoolstof.

G. Stahel, 1941. Een feest bij de Trio-Indianen. De Surinamer I94I, 20 Oct., 4 pp.

De, bijna woordelijk gelijke beschrijving van dit feest, dat Baas SснміDт op zijn tweede (niet de laatste!) reis in het Trio-dorp Piké, nabij de Zuidgrens bijwoonde, is te vinden op blz. 20-22 van Stahel's ,Verslag van drie reizen naar de Bovenlandsche Indianen door LoDEWIJK SCHMIDT", 1942. 
Gerold StAHEL, 1942. De nuttige planten van Suriname. Bull. Landbouwproefst. Suriname 57, 197 pp.

Dit werk heeft een te rijken inhoud, dan dat hier méér dan een korte aankondiging zou kunnen worden gegeven. Toch zal dit boek - met allen eerbied voor de ontzaglijke hoeveelheid kennis van land en volk welke er in is neergelegd - met een indeeling die geheel op de praktijk is gericht, zònder determinatie-tabellen en zònder afbeeldingen, velen niet bevredigen. Moge deze publicatie dan ook een opwekking, en geen rem zijn, voor een uitgave over hetzelfde onderwerp, welke meer kan worden vergeleken met de monumentale werken die wij over de nuttige planten van Oost-Indië bezitten.

Gerold Stahel, 1942. Verslag van drie reizen naar de Bovenlandsche Indianen door LODEWIJK SchMidT. Bull. Landbouroproefstat. Suriname 58, 64 pp., fig., 7 tabb.

Tot op heden waren de meeste Oajana-dorpen aan de Braziliaansche zijde van de grens, alsmede de meeste Trio-dorpen nog nooit door reizigers bezocht. Toen het wenschelijk bleek een algemeen overzicht over de daar heerschende toestanden te verkrijgen, werd dit onderzoek toevertrouwd aan baas Lodewijк Schмidт van Gansee, die op alle grensexpedities als hoofdman en magazijnmeester was mee geweest en dientengevolge het grensgebied reeds uit eigen aanschouwing kende.

Van de hem opgedragen taak heeft baas SснміDт zich op een lofwaardige wijze gekweten. Van de 20 Oajana-dorpen heeft hij er 16, van de 25 Trio-dorpen er 20 bezocht, op drie reizen, die binnen $11 / 2$ jaar werden volbracht (Oct. '40-April '42). - Op grond van zijn tellingen wordt aangenomen dat er heden niet meer dan 400 Oajana's zijn, de eene helft in Suriname, de andere in Brazilië, en niet meer dan 750 Trio's, waarvan $1 / 3$ in Suriname.

Van Schmidr's mededeelingen maakte Stahel een eenvoudig en, ondanks zijn strenge zakelijkheid, goed leesbaar reisverslag, dat ons een treffend, doch helaas niet zeer opgewekt beeld geeft van de toestanden welke op het oogenblik nabij de Zuidgrens heerschen.

Gerold Stahel, 1943. The fungus gardens of the leaf-cutting ants. Journ. N. York Bot. Garden 44, p. 245-253, 6 figg.

Een boeiende beschrijving met mooie afbeeldingen van het wonder der schimmeltuinen bij de parasolmieren; een aardig sluitstuk op het prachtige onderzoek dat, in samenwerking met dr. GriJSKES werd verricht en waarmede het Dept. Landbouwproefstation Suriname alle eer inlegt.

Gerold Stahel, 1944. The jungle tree of dangling seeds. Journ. N. York Bot. Garden 45, p. 265-268, 2 figg.

De bloemen van Swartzia prouacensis zijn nauwelijks meer dan $2 \mathrm{~mm}$ 
groot maar vormen later peulen van ongeveer $3 \mathrm{~cm}$ lengte. Als de rijpe vrucht openspringt, valt er een bruinachtige boon uit die aan een dunne, tot $3 \mathrm{~m}$ lange navelstreng blijft hangen. Onder de kruin van een ijzerhart-boom kan men zoo soms honderden zaden zien bengelen.

Gerold Stahel, 1944. Notes on the Arawak Indian Names of plants in Surinam. Journ. N. York Bot. Garden 45, p. 268-275, 278-279, 3 figg.

Een van de afbeeldingen is het protret van BAPTIST, den Arawak, van wien de meeste namen afkomstig zijn.

Gerold Stahel, 1944. De nuttige planten van Suriname. Bull. Landbouwproefst. Suriname 59, 239 pp.

Vele hoofdstukken zijn grooter geworden en soms anders ingedeeld. Het meest uitgebreid is de behandeling van de houtsoorten. Stellig zal dit werkje er veel toe bijdragen, en reeds hebben bijgedragen, om Suriname en zijn producten beter te leeren kennen.

Stahel, (z.j.: 1944). Surinam timbers. (Landbouwproefstation Suriname), $39 \mathrm{pp}$.

Een klein boekske,samengesteld op verzoek van enkele Surinaamsche houthandelaren, waarin een zeer korte beschrijving wordt gegeven van 34 inlandsche houtsoorten, met aanwijzingen voor hun gebruik.

Gerold Stahel, 1944. Het Boschnegervraagstuk en het Coronieplan. Meded. Landbouwproefst. Suriname 9, 28 pp.

De schrijver - die gelegenheid had, van dichtbij en vanuit de lucht, de landbouwtoestanden bij de Boschnegers te bestudeeren zag hoe de verkwistende cultuurmethoden van de Boschnegers, in de door parasolmieren besmette gebieden, een ,,permanente mierenkapoewerie" deden ontstaan, welke in het algemeen ongeschikt is voor het planten van voedingsgewassen - in tegenstelling met de methoden der Bovenlandsche Indianen, waarbij de mieren worden ontvlucht voordat zij ernstig kwaad hebben gedaan, zoodat het weder opgroeiende bosch de dieren nog kan verstikken.

Laat men deze ontwikkeling zijn gang gaan, dan zal - zoo berekent Stahel - binnen 20 jaren de reserve aan vruchtbaar land in de Boschnegergebieden van de Suriname en de Saramacca op raken, en na omstreeks 120 jaren zullen al de, voor cultures geschikte gebieden van de Surinaamsche binnenlanden zijn verbruikt en in vrijwel waardelooze mieren-kapoewerie veranderd. Kunnen ,,de Boschnegers, die zich in dien tijd waarschijnlijk tot het 5-voudige zullen hebben uitgebreid, niet naar de buurlanden, vooral Demerara, uitwijken, dan zullen ze naar het kustgebied moeten komen, waar ze in zoo grooten getalle en in korten tijd onmogelijk kunnen worden geassimileerd." Daarom wordt ,,voorgesteld het wegtrekken der Boschnegers naar de westelijke binnenlanden geheel te beletten en hun in plaats daarvan extra hiervoor in te richten vestigingsplaatsen in Coronie aan te bieden 
teneinde ze aan de Coronianen te doen assimileeren. Ze zullen dan, ten minste de daar opgegroeide generatie, ophouden Boschnegers en parasieten op ons land te zijn en geschikt worden gemaakt om opgenomen te worden in de creoolsche volksgemeenschap van Suriname".

Een grootsch plan! - dat ons zonder meer stelt voor een ontstellende hoeveelheid, soms schier onoplosbaar of zelfs niet eens aanvaardbaar gelijkende maatschappelijke problemen en dat daarom door velen stellig voor niet mogelijk zal worden gehouden. Zèlfs indien men vertrouwen heeft in de grondslagen van STAHEL's betoog en daarbij gelooft in een permanente mierenkapoeweri, waarvan het bestaan echter nog zal moeten worden bewezen.

G. Stahel \& D. C. Geijskes, 1940. Drie verkenningsvluchten boven Suriname's binnenlanden met het K.L.M.-vliegtuig „,De Snip”. Tijdschr. Ned. Aardr. Gen. (2) 57, p. 441-456, 2 tabb., 2 kaarten.

Een verslag van drie vluchten van 6-7 u, op 16, 17 en 18 Oct. 1939, naar de groote savannen aan de Zuid-grens, waarbij veel belangwekkende waarnemingen werden verricht. Men kreeg een uitstekende kijk op den bouw van den machtigen Tafelberg, vloog over het, uit de lucht wel zeer merkwaardige Coeroeni-landschap, ontdekte een schijnbaar geschikt landingsterrein op de Paroe-savanne en zag met angstwekkende duidelijkheid, hoe de valleien van de Boven-Suriname en de Saramacca door de Boschnegers, in samenwerking met de parasolmieren, van hun vruchtbaarheid werden beroofd.

Gerold Stahel \& D. C. Geijskes, 1940. De parasolmieren en hunne bestrijding. Bull. Landbouwproefst. Suriname 56, 26 pp., 2 tabb.

In kort bestek wordt ons hier op een zakelijke en toch prettig leesbare wijze veel belangwekkends verteld over de beide, in Suriname voorkomende soorten van parasolmieren (Atta cephalotes, de mier van het laagland en Atta sexdens, de bewoner der hoogere, binnenlandsche gronden), waarbij achtereenvolgens de soortverschillen, de verschillende vormen waarin de mieren in hetzelfde nest voorkomen, de bewonderenswaardige organisatie van den staat der parasolmieren, de bouw der nesten en het ontstaan van nieuwe nesten worden behandeld. Deze kennis van het doen en laten der parasolmieren is een eerste vereischte om te kunnen komen tot een doelmatige bestrijding, waaraan de laatste 6 bladzijden zijn gewijd en waarin de verdelging met water en met zwavelkoolstof in het bijzonder wordt besproken.

De bestrijding van deze groote landbouwplaag is alleen dan op afdoende wijze uit te voeren, indien wordt gewerkt met vaste bestrijdingsploegen, waarbij een zoo volledig mogelijk bebouwd gebied in behandeling wordt genomen.

De afbeeldingen geven een goed beeld van den ingewikkelden bouw van het nest van Atta cephalotes en $A$. sexdens en toonen enkele in het oog springende verschillen tusschen de werksters en de soldaten van 
beide soorten. In de inhoudsopgave moeten alle bladzijde-verwijzingen met 2 worden vermeerderd.

De waarde van dit boekje wordt aanzienlijk verhoogd door het feit, dat het niet slechts de vrucht is van een ijverige literatuurstudie, maar ook van een uitgebreid veld- en laboratorium-onderzoek van de beide schrijvers.

Gerold Stahel \& D. C. GeijSkes, 1940. Observations about temperature and moisture in Atta-nests. Revista Entomol. II, 766-775, 6 figg.

Een nauwkeurig onderzoek, waarin wordt aangetoond, dat de temperatuur in de schimmeltuinen van de Atta-nesten - in tegenstelling met de bestaande vermoedens - niet hooger is dan van de omgeving.

G. Stahel \& D. C. GeijSkes, 1940. De zand- en schelpritsen. De Surinamer I940, 20 Dec., 4 pp.

Een voorloopige mededeeling, die, naast enkele belangwekkende beschouwingen over het ontstaan van het Surinaamsche kustland, enkele resultaten geeft van een nauwkeurig onderzoek van de ritsen ten Noorden van Paramaribo. Het is merkwaardig, dat - hoewel de ritsen ook in Demerara en elders, waar een lage kust met een ondiepe zee voorkomt, worden aangetroffen - over den bouw van deze merkwaardige vormingen, tot dusver nog zoo uiterst weinig bekend was.

Gerold Stahel \& D. C. Geijskes, 1941. Weitere Untersuchungen über Nestbau und Gartenpilz von Atta cephalotes L. und Atta sexdens L. (Hym. Formicidae). Revista Entomol. 12, p. 243-268, 9 figg., tab. 15-19.

In een vroegere mededeeling (Rev. Ent. Io, 1939) werd reeds het resultaat van een systematisch onderzoek naar den bouw van de nesten der parasolmieren medegedeeld. (Besproken in W.I. Gids, 23, jrg. 22, p. 191). Deze publicatie heeft ten doel onze kennis van de buitengewoon mooie en ingewikkelde organisatie van de Atta-staat nog meer te verdiepen. In het mycologische deel wordt het bewijs geleverd dat de schimmel, die door de mieren wordt gekweekt, een basidiomyceet is, behoorende tot het geslacht Rozites, waarvan de paddestoel slechts uiterst zelden tot ontwikkeling komt.

Verslag over de jaren 1938 en 1939. Departement van Landbouw-Economische Zaken Suriname (z.j. : 1940?), 163 pp., 17 figg., 4 tabb.

De inhoud van dit verslag is te veelzijdig dan dat hier een volledig beeld over den inhoud zou kunnen worden gegeven. Het bevat o.m. artikelen over: Weersgesteldheid; toestand van den landbouw (blz. 11-23), citruscultuur (blz. 24-68, met een groot rapport van J. D. 
OPPENHEIM); koffie (blz. 69-79, met proeven over verbetering van de liberia-koffie en een nieuwe pulpmethode); rijstcultuur (blz. 80-108, met een rapport van TAN SiN Houw, over kwaliteitsverbetering van gepelde rijst, en met een nieuwe methode voor de bereiding van gestoomde rijst); bacoven en visscherij.

Verslag over het jaar I940. Departement van LandbouwEconomische Zaken Suriname (z.j. : 1941 ?), 145 pp., 5 figg.

Met verslagen over: Weersgesteldheid; toestand van den landbouw ; werkzaamheden landbouwscheikundige (H. J. Muller, blz. 20-36); irrigatiedienst ( J. J. vaN Wouw, blz. 37-45); werkzaamheden tuinbouwkundig ambtenaar (E. J. UHLENBECK); citruscultuur (J. D. OPPENHEIM, blz. 52-66); werkzaamheden landbouwleeraar (W. E. HEwiтT); ontwikkeling van den landbouw in Nickerie (H. L. H. Sснürz, blz. 88-100); aandoeningen van ananas (J. URI, blz. 105-114) en visscherij (J. Diemont, blz. 133-138).

Verslag over het jaar I94I. Departement van LandbouwEconomische Zaken Suriname (z.j. : 1943), 159 pp., 5 figg.

Hierin wordt o.m. behandeld: Weersgesteldheid, toestand van den landbouw; werkzaamheden landbouwscheikundige (H. J. Muller, blz. 17-43, waaronder grondonderzoek, wateronderzoek); verslag landbouwconsulent (E. J. UHLENBECK, blz. 44-63); citruscultuur (J. D. Oppenheim, blz. 64-86), verslag landbouwleeraar (W. E. HewitT en H. SсHÜTz, blz. 87-107), verslag veearts (J. Frickf Rs, 108144). 